\title{
Dielectrophoretic Manipulation of Particles for Use in Microfluidic Devices
}

\author{
R. Miles \\ P. Belgrader \\ K. Bettencourt \\ J. Hamilton \\ S. Nasarabadi \\ This paper was prepared for submittal to the \\ International Mechanical Engineering Congress and Exposition 299 Microfluidics Symposium \\ Nashville, Tennessee \\ November 14 - 19, 1999
}

June 1999

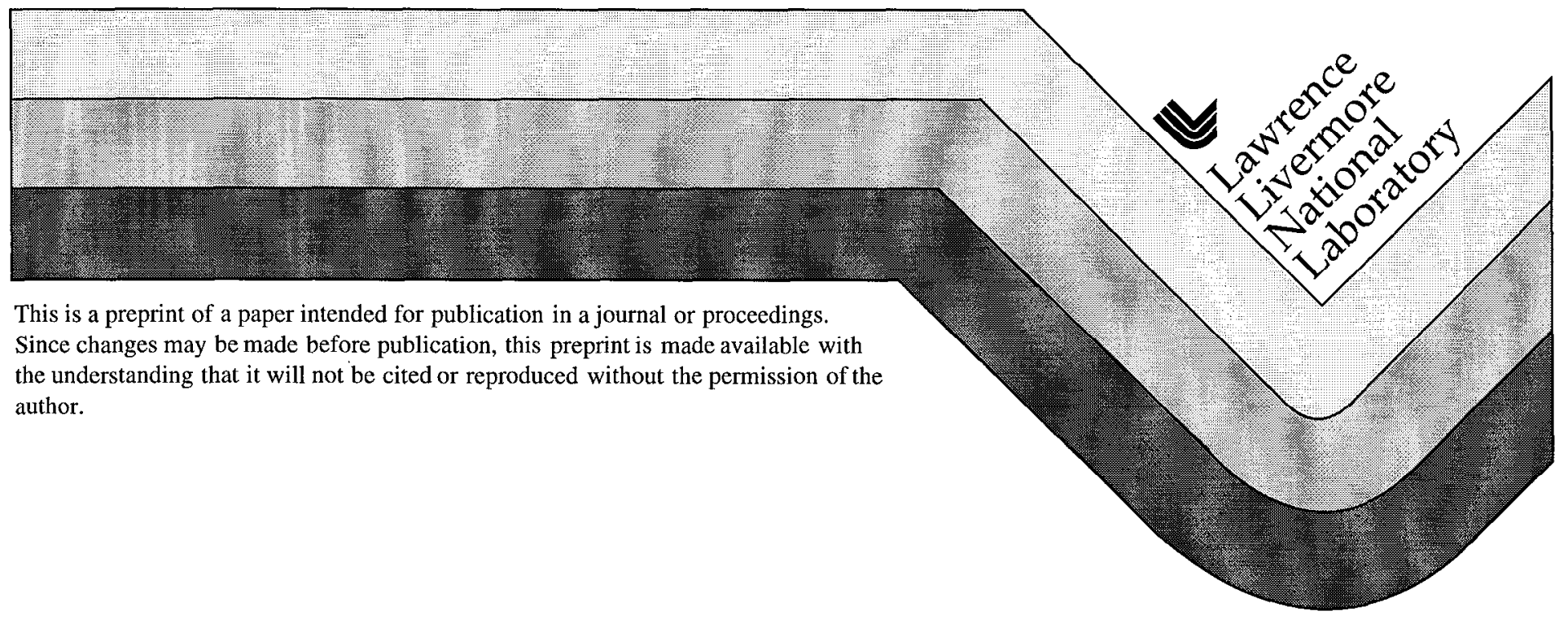




\section{DISCLAIMER}

This document was prepared as an account of work sponsored by an agency of the United States Government. Neither the United States Government nor the University of California nor any of their employees, makes any warranty, express or implied, or assumes any legal liability or responsibility for the accu racy, completeness, or usefulness of any information, apparatus, product, or process disclosed, or represents that its use would not infringe privately owned rights. Reference herein to any specific commercial products, process, or service by trade name, trademark, manufacturer, or otherwise, dues not necessarily constitute or imply its endorsement, recommendation, or favoring by the United States Government or the University of California. The views and opinions of authors expressed herein do not necessarily state or reflect those of the United States Government or the Lniversity of California, and shall not be used for advertising or product endorsement purposes. 


\title{
DIELECTROPHORETIC MANIPULATION OF PARTICLES FOR USE IN MICROFLUIDIC DEVICES
}

\author{
Robin Miles, Phil Belgrader, Kerry Bettencourt, Julie Hamilton, \\ Shanavaz Nasarabadi \\ Lawrence Livermore National Laboratory, \\ 7000 East Ave L-223, Livermore, CA 94550 \\ Tel: 925-422-5048 Fax: 925-422-2373, Email: miles7@1lnl.gov
}

\begin{abstract}
Amplification and hybridization of DNA are commonly used techniques to verify the presence of a specific DNA sequence in a test sample. Automatic sample handling to concentrate and purify sample prior to amplification is desirable both from the cost standpoint and from the standpoint of reducing the possibility of sample contamination. This paper explores the use of the dielectrophoretic force to manipulate DNA, Bacillus globigii spores, and Erwinia herbicola bacteria to provide concentration and purification as part of the sample handling functions in biological monitoring equipment. It was found that for what would be considered a typical microfabricated structure with electrode gaps at $30 \mu \mathrm{m}$ operating at $5 \mathrm{~V}$, that concentration of the particles is very effective.
\end{abstract}

\section{INTRODUCTION}

The use of fluidic microchips to perform integrated sample preparation for biological assays is currently an area of significant interest which promises to reduce costs of biological testing through automation of manual operations and reduced reagent use. Polymerase chain reaction (PCR) amplification of DNA is becoming a common technique in biological assays involved in deciphering segments of the genetic code. Optimal DNA amplification protocols include such sample preparation tasks as concentration of cellular sample, lysing of the cells, cxtraction of the DNA from the lysing solution and extraneous cellular material, addition of reagents, and thermal cycling. Concentration and purification of the sample are desirable to reduce reagent use and to increase the probability of a successful amplification. However, these are two of the more difficult tasks to achieve in an automated sample preparation system. The traditional sample preparation method to concentrate cellular sample is to centrifuge the sample and remove the supernatant, leaving a concentrated set of solids at the bottom of a test tube. Clearly this task is not amenable to the microchip approach to biological assay development. DNA purification usually involves the introduction of glass bcads to which the DNA attaches itself. The beads can be filtered from the morass of lysates and heated to release the DNA prior to the introduction of PCR reagents. The microfabrication of filters is challenging task and the prospects of such a device for longterm use are poor due to the potential of clogging over time.
It is possible to move biological particles independently of the fluid flow field using the diclectrophoretic force imposed on the particles by local non-uniform electric fields. By separating the motion of the fluid from the that of the particles, the particles can be concentrated within small region defined by the electric field. The particles can then be released by simply removing the electric field. Particles can thus be electronically filtered from a large sample volume. The particles remain captured while lysing solution is introduced into the fluid stream. The DNA can be captured from the flowing stream. Using an electric field to hold the particles of interest, concentration and purification of sample is accomplished. Physical filters which my clog are avoided.

In general, there are two major techniques for manipulating particles within an electric field; electrophoretically and dielectrophoretically (DEP). Electrophoretic separation is an important analytic tool used extensively to separate particles such as DNA and proteins to determine the molecular constituents of a sample. A DC voltage is typically applied to the ends of a capillary tube or channel and the particles move according to their size and charge. The electrophoretic force is generally too small in comparison to the hydrodynamic forces on the particles to separate the particles from the flowing media. In contrast, the dielectrophoretic force is not a function of native charge, but of the ability of a particle to bccome polarized in the presence of an electric field. If placed within a non-uniform field, particle polarized by the field will be attracted to areas of high or low field gradient depending on it, electrical properties relative to those of the suspending media. This force is applicable in both AC and DC fields. The force is highly dependent on the electrical properties of both the suspending media and the particles. These properties in turn are a strong function of the frequency of excitation.

The dielectrophoretic force on a spherical particle can be expressed (Pohl,1980) as

$$
F_{\mathrm{DEP}}=-4 \pi \varepsilon_{\mathrm{m}} \mathrm{r}^{3} \operatorname{Re}\left\{\mathrm{f}_{\mathrm{m}}\right\} \nabla \mathrm{E}_{\mathrm{rms}}^{2}
$$

where $\varepsilon_{\mathrm{m}}$ is the permittivity of the medium in which the particle is suspended, $f_{m}$ is the Clausius-Mossoti factor, $r$ is the particle radius, and $E$ is the electric field. The Clausius-Mossoti factor is expresses as 
$f_{\mathrm{m}}=\left(\varepsilon_{\mathrm{p}}{ }^{*}-\varepsilon_{\mathrm{m}}{ }^{*}\right)\left(\varepsilon_{\mathrm{p}}{ }^{*}+2 \varepsilon_{\mathrm{m}}{ }^{*}\right)$

where $\varepsilon_{\mathrm{p}}^{*}$ is the complex permittivity of the particle given by $\varepsilon^{*}=\varepsilon-\mathrm{j} \sigma / \omega$ where $\varepsilon$ is the permittivity, $\sigma$ is the conductivity, and $\omega$ is the angular frequency. Likewise, $\varepsilon_{\mathrm{m}}{ }^{*}$ is the complex permittivity of the medium. The ClausiusMossoti factor is a strong function of frequency for biological particles. Typical walled biological particles exhibit positive DEP at low frequencies in low conductivity solutions and negative DEP at higher frequencies. Cells without walls exhibit a mid-frequency region of positive DEP, while negative DEP is characteristic of low and high frequency operation. (Jones,1995) Positive DEP is useful for the concentration of particles.

Many biological and other particles of interest are polarizable. In this paper, we will present data on the use of dielectrophoresis to concentrate Bacillus globigii (B.g.) spores, Erwinia herbicola (E.h.) bacteria, DNA molecules, and polystyrene beads, in sterile deionized water.

The use of the dielectrophoretic force is attractive in microchips because the field strengths achievable on the millimeter and less scales in microfluidic devices are useful using only a few volts applied to the electrodes. A system was built to determine the frequencies at which these particles interact with the electric field. The interaction in both static and in flowing systems was tested.

\section{EXPERIMENTAL PROTOCOL}

Scparate test devices were fabricated for tests of dielectrophoretic capture of particles in flowing versus non-flowing water. Nonflow devices consisted of electrodes deposited on glass using standard photolithographic methods (Kovacs, 1998). A sample device is shown in Fig. 1. The interdigitated electrodes are 2.2 $\mathrm{cm}$ long, $50 \mu \mathrm{m}$ wide with a $30 \mu \mathrm{m}$ spacing between the electrodes. The electrodes consist of $20 \mathrm{~nm}$ of chromium under $200 \mathrm{~nm}$ of gold. Wire leads were soldered to the electrodes to provide the excitation signals. The sample was placed on the glass/electrode surface and a standard $2.2 \mathrm{~cm}$ X $2.2 \mathrm{~cm}$ microscope coverslip placed over the sample before viewing via a microscope. An amplified AC voltage is applied between the electrodes and visual observation through a microscope is used to determine trapping of the biological particles. Typical DNA specimens consisted of $10 \mu \mathrm{l}$ DNA in concentrations of 500 $\mu \mathrm{g} / \mathrm{ml}$ was stained using $1 \mu \mathrm{l}$ of $1 \mathrm{mM}$ YOYO-1 dye from Molecular Probes diluted 10:1. DNA originally purchased suspended in Tris-EDTA solution were dyed and resuspended in sterile deionized water. Bacillus globigii and Erwinia herbicola were used in concentrations of $10^{8}$ particles $/ \mathrm{ml}$. Polystyrene beads were used in concentrations of $10^{5} / \mathrm{ml}$. A small amount of surfactant, $0.05 \%$ Tween 20 was added to prevent sticking of the particles to the glass/electrode surface. It was noted that after some minutes of working with B.g., the DEP force would decrease probably due to a build-up of organic material. Exposure of the plate to oxygen plasma etch at $150 \mathrm{~W}$ for 2 minutes would rejuvenate the surface.
Tests of dielectrophoretic trapping of particles in flowing deionized water were made using a similar process. Electrodes were photolithographically patterned on a 4" glass wafer. The electrodes were $30 \mu \mathrm{m}$ wide with $30 \mu \mathrm{m}$ spacing and about 1 $\mathrm{cm}$ long to cover roughly a $1 \mathrm{~cm}^{2}$ area. Flow channels were created by cutting the desired channels of roughly $.5 \mathrm{~cm}$ width in a sheet of $100 \mu \mathrm{m}$ thick Parafilm wax film. The film was sandwiched between the patterned glass wafer and an additional glass wafer with holes drilled into in for fluid access to the channels. The assembly is placed within a fixture as shown in Fig. 2 which provides an interface to external syringe pumps. Spring-loaded pogo pins soldered into a PC board are used to provide the electrical connections to the patterned electrodes. An AC signal of varying frequency $(10 \mathrm{~Hz}$ to $3 \mathrm{Mhz})$ and voltage $\left(0-5 V_{\mathrm{ms}}\right)$ is placed across the interdigitated electrodes. Particles at concentrations similar to those used in the no-flow tests were suspended in deionized water and forced through the channel at a rate determined by the syringe pump. Observation through the microscope is used to determine the approximate percentage of particles within about $25 \mu \mathrm{m}$ of the channel surface that adhere to the electrodes. At intervals the electric field is removed to determine the numbers of particles trapped in the field versus the number which may have adhered to the surface through surface-molecular interactions.

\section{TEST RESULTS}

Figure 3. demonstrates the capture of B.g. along the edges of the interdigitated electrodes at the regions of high field gradient. A graph of the frequencies where similar positive dielectrophoretic concentration is shown in Fig. 4 for various lengths of DNA, B.g., E.h., and $1 \mu \mathrm{m}$ polystyrenc beads in sterile deionized water. For the $30 \mu \mathrm{m}$ gap electrodes, $5 \mathrm{~V}_{\mathrm{ms}}$ applied voltage, we found no dielectrophoretic trapping of DNA less than $8 \mathrm{Kbp}$ in length. We found DNA trapping easiest at lower frequencies, around $100 \mathrm{~Hz}$. to $1 \mathrm{KHz}$. At lower frequencies $(<500 \mathrm{~Hz}$.) bubble nucleation due to hydrolysis limits the excitation voltage. B.g. spores were effectively captured by the field at frequencies ranging from $1 \mathrm{KHz}$. to 3 $\mathrm{MHz}$. to in water. E.h. bacteria were also effectively captured at the higher frequencies. These organisms are larger and presumably would exhibit a larger effective;ipole that the DNA moleculcs. Polystyrene beads were captured only at very low frequencies. The relative dielectric constant for polystyrene is much less than water (2 vs. 80$)$ and thus negative dielectrophoresis is expected particularly at the higher frequencies where dielectric properties dominate.

Figure 5. shows the approximate percentage of particles captured from a flowing stream of sterile deionized within about $25 \mu \mathrm{m}$ of the electrode surface as determined by the focal length the of microscope objective. A similar plot is shown for 48 Kbp DNA in Fig. 6. The ability of the DEP force to remove particles from the stream decreases within increasing stream velocity as might be expected. B.g. was much easier to capture than the DNA as indicated by the much greater flow stream velocities of capture. This is again probably the result the larger effective polarizability of the organism versus a puny 
molecule. While some information about the precise electrical properties of some types of cells have been gleaned using electrorotaion spectra (Gascoyne, 1994) such is not the case for single molecules such as DNA.

Figure 7 depicts the practical results of concentration of B.g. using the dielectrophoretic force. Figure Xa shows electrodes covered with B.g. captured from a stream of B.g. at $10^{8}$ spores $/ \mathrm{ml}$ concentration over the period of about 5 minutes. Figure $\mathrm{Xb}$ shows an identical set of electrodes upstream of the collection electrodes which are inactivated and therefore do not collect B.g. material. The B.g. in the picture are suspended in the flow stream. Figure 8 depicts collected sample of YO-YO decorated E.h. DNA after introduction of lysing solution into the surrounding fluid. The degree of purification of the DNA will depend on the degree of entanglement of the DNA with other cellular material.

\section{CONCLUSION}

The use of dielectrophoretic forces have been demonstrated to aid in the concentration of biological samples. In particular, we have demonstrated the concentration of a spore (B.g.) a bacteria (E.h.) and DNA molecules. Dielectrophoretic concentration is a useful feature for any biological test where it is important either to reduce reagent use or to purify the sample. These techniques are particularly useful in automated microfabricated sample preparation systems because they use standard microfabrication methods and they do not obstruct flow permitting long term, clog-free use of the structures.

\section{ACKNOWLEDGMENTS}

The authors would like to acknowledge the support of Ray Mariella, director of the Center for Microtechnology at LLNL. This work was perfomed under the auspices of the U.S. Dept. of Energy by Lawrence Livermore National Laboratory under contract W-7405-ENG-48.

\section{REFERENCES}

Cheng, J., Sheldon, E.L., Wu, L. Uribe,A., Gerrue , L.O. , Carrino, J., Heller, M.J., O'Connell, JP., June 1998, "Preparation and Hybridization Analysis of DNA/RNA from E.Coli on Microfabricated Bioelectronic Chips, Nature Biotechnology, Vol. 16, pp 541-546.

Washizu, M. , Kurosawa, O. , Nov/Dec 1990, "Electrostatic Manipulation of DNA in Microfabricated Structures", IEEE Transactions on Industry Applications, Vol. 26, No. 6,pp. 1165- 1171.

Morishima, K., Fukuda, T., Arai , F., Yoshikawa, K., 1996, "Microflow Sytstem and Noncontact Transporation of DNA Molecule in Microflow Channels by Dielectrophoretic Force", Microelectromechanical Systems, DSC -Vol. 59, ASME, pp. 339-344.
Washizu, M. , Kurosawa, O., Arai, I., Suzuki, S. , Shimamoto, N., May/June 1995, "Applications of Electrostatic Stretch and Positioning of DNA", IEEE Transactions on Industry Applications, Vol. 32 , No. 3, pp.447-455.

Washizu, M. , Suzuki, S. , Kurosawa, O., Nishizaka, T., Shinohara ,T., July/August 1994, "Molccular Dielectrophoresis of Biopolymers", IEEE Transactions on Industry Applications, Vol. 30, No. 4, pp. 835-842.

Morishima, K., Fukuda, T., Arai , F., Yoshikawa, K., 1997, "Microflow Sytstem and Transportation of DNA Molecule by Dielectrophoretic Force Utilizing the Conformal Transition in the Higher Order Structure of DNA Molecule", IEEE publication 0-7803-3744, pp. 389-394.

Gascoyne, P.R.C. , Noshari, J., Becker, F F. , Pethig, R., ", July/August 1994, "Usc of Diclectrophorctic Collection Spectra for Characterizing Differences between Normal and Cancerous CellsIEEE Transactions on Industry Applications , Vol. 30, No. 4, pp.829-834,

Asbury, C.L. , Ger van den Engh, Feb. 1988, "Trapping of DNA in Nonuniform Oscillating Electric Fields", Biophysical Journal, Vol. 74 , pp. 1024-1030.

Kovacs, G.T.A., 1998, Micromachined Transducers Sourcebook, McGraw-Hill, New York, N.Y., pp. 98-100.

Jones, T., 1995, Electromechanics of Particles, Cambridge University Press, New York, N.Y.

Figure 1. Sample device for observing static dielectrophoretic capture of particles. 
Figure 2. Device for testing DEP concentration of particles suspended in water.

Figure 3. DEP capture of B.g. along the electrode edges.

Figure 4. Frequencies at which positive DEP was observed for particles in water.

Figure 5. Approximate percentage of B.g. particles captured from flowing water.

Figure 6. Approximate percentage of $48 \mathrm{Kbp}$ DNA captured from flowing water

Figure 7a. B.g. collected on activated electrodes from flowing water

Figure 7b. Unactivated electrodes in water with B.g. suspension.

Figure 8. DNA from lysed E.h. captured along electrode edges using $D E P$. 


\section{Figure 1}

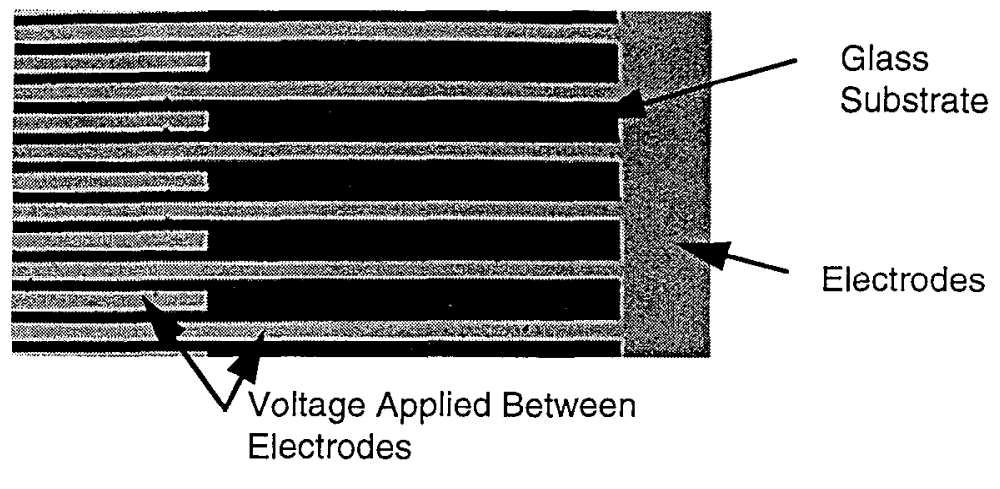




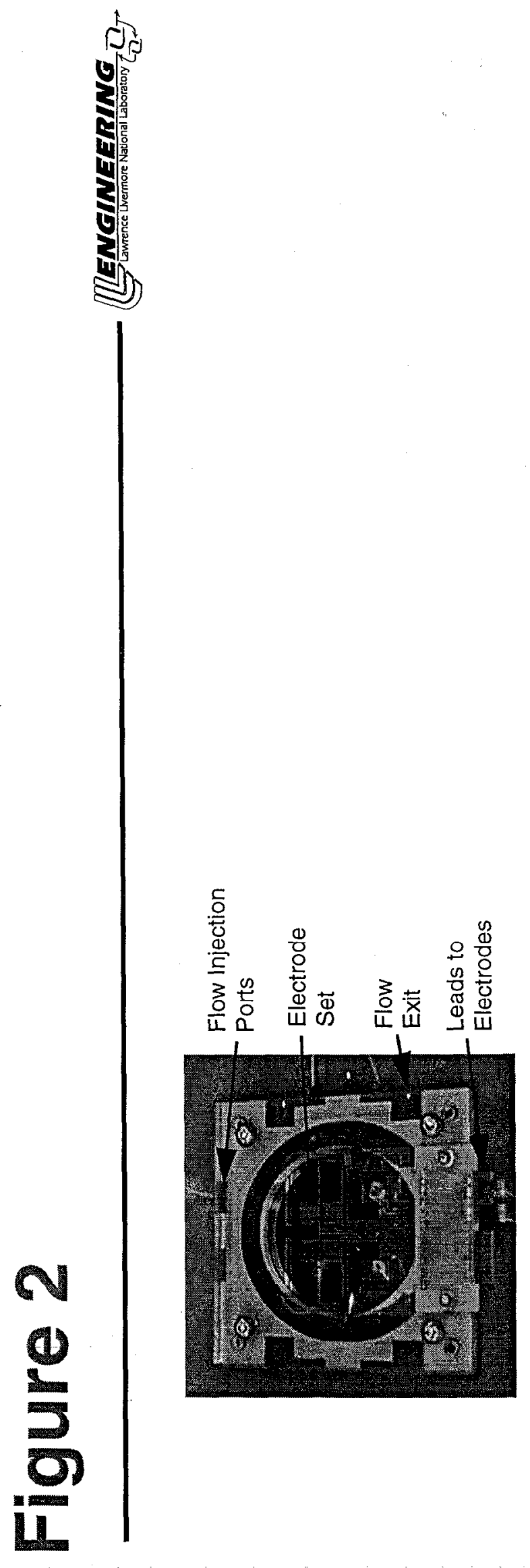




\section{Figure 3}

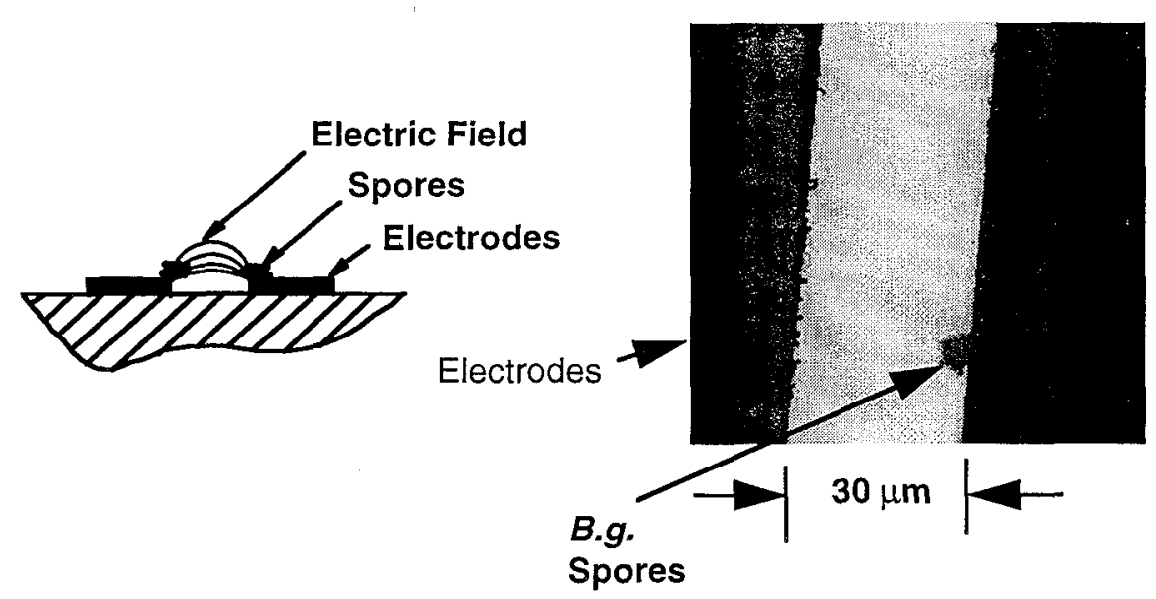




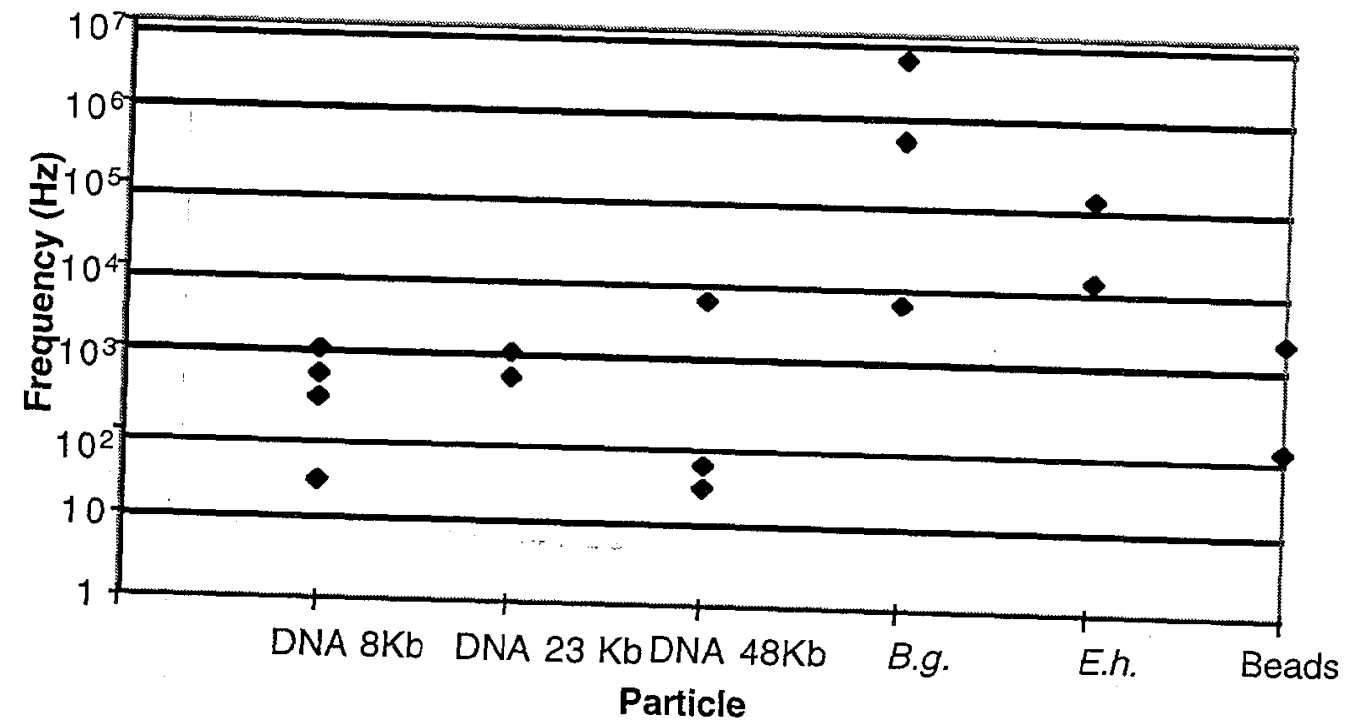




\section{Figure 5}

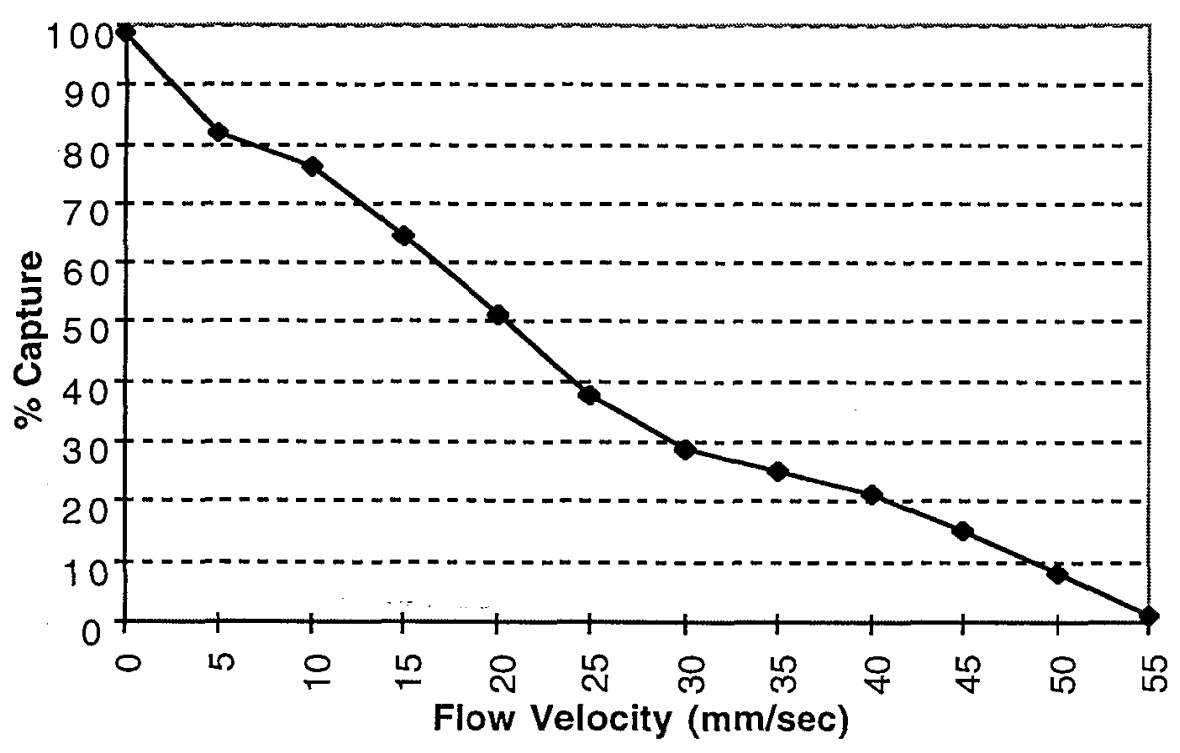




\section{Figure 6}

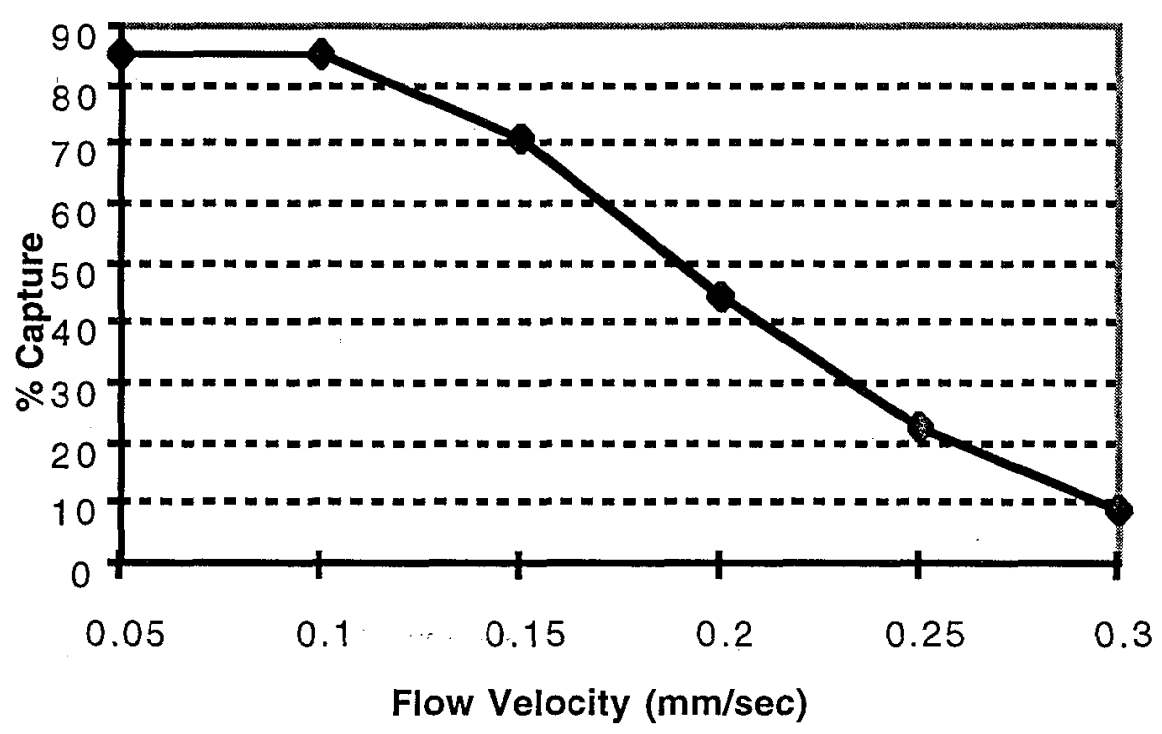




\section{Figure $7 a$}

ILENGINEERING

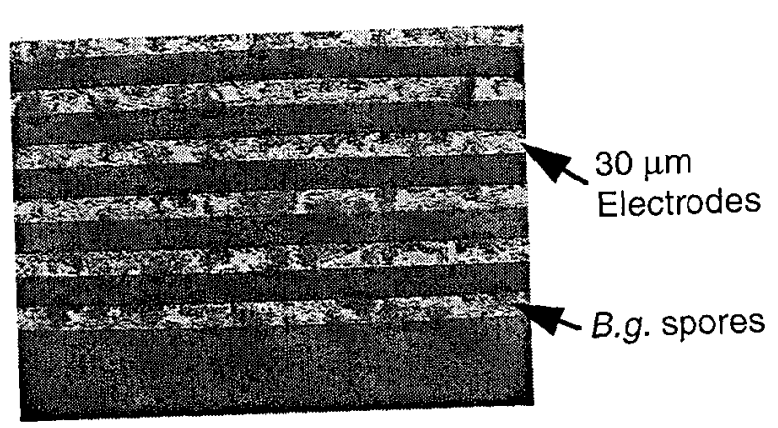




\section{Figure 7b}

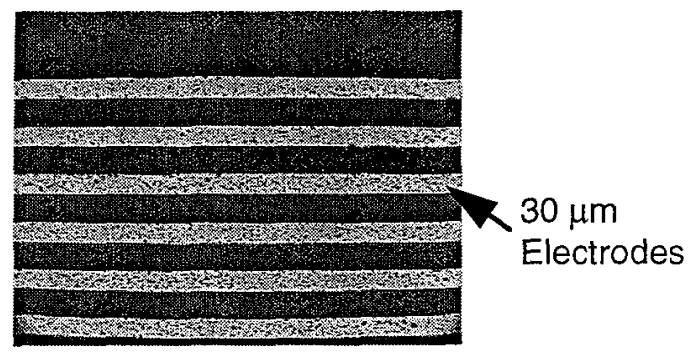




\section{Figure 8}

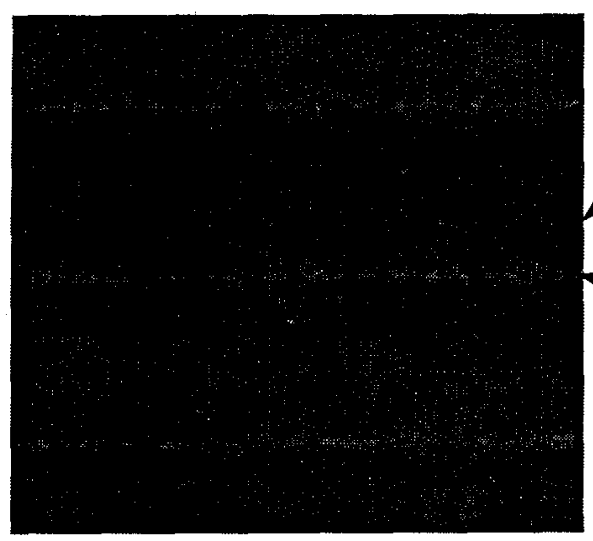

$30 \mu \mathrm{m}$

Electrodes

- Fluorescently-

labeled E.h.

DNA 